\title{
The Optimization of Ultrasonic Extraction for Benzoic Acid Determination in Curry Paste Samples by Using UV-Visible Spectrophotometry
}

\author{
Nararat Thongsrinoon ${ }^{1, a *}$, Patcharida Naun-Ong ${ }^{1}$ and Yuwalita Ketyothin ${ }^{1}$ \\ ${ }^{1}$ Chemistry and Applied Chemistry Program, Faculty of Science and Technology, \\ Songkhla Rajabhat University, Thailand \\ atnararat@yahoo.com
}

\begin{abstract}
Keywords: benzoic acid, curry paste, ultrasonic extraction, UV-Visible spectrophotometry
\end{abstract}
\begin{abstract}
The main factors affecting ultrasonic extraction, such as extraction solvent, extraction temperature and extraction time were optimized for benzoic acid determination by using UV-Visible spectrophotometer at a wavelength of $230 \mathrm{~nm}$. Under the optimum conditions of ultrasonic extraction, linearity between the concentration of benzoic acid in spiked curry paste samples and the absorbance was obtained in the concentration range from 100 to $2,000 \mathrm{mg} / \mathrm{kg}$. Recoveries for benzoic acid determination were obtained range from 74.67 to $95.33 \%, 71.78$ to $97.56 \%$ and 88.00 to $106.45 \%$ with R.S.D. were 1.05 to $5.47 \%, 0.92$ to $4.27 \%$ and 0.71 to $4.22 \%$, when spiked red curry paste, southern red curry paste and southern sour curry paste samples were analyzed, respectively.
\end{abstract}

\section{Introduction}

Curry paste is an important ingredient in Thai curries such as green curry, red curry and sour curry, which are the popular and favorite Thai cuisines. Curry paste is made from chili peppers, dry chili peppers, garlic, shallots, lemongrass, galangal, salt and shrimp paste. Depending on the type of curry, additional ingredients such as pepper, turmeric, cilantro root, coriander and cumin, or other ingredients are also included. The ingredients are ground together, traditionally with a mortar and pestle or non-traditionally with an electric food blender. Nowadays, consumers prefer to buy readymade foods including curry pastes from the marketplace rather than making them by themselves. While being processed and stored, preservatives are added to stop or delay nutritional losses due to microbiological, enzymatic or chemical changes of food during its shelf life [1].

Benzoic acid is permitted for use as a preservative in a wide variety of foods. Benzoic acid, particularly the undissociated acid form, retards the growth of yeast and moulds [2]. Under the "Codex General Standards for Food Additives" (GSFA, Codex STAN 192-1995) adopted by Codex Alimentarius Commission (CAC), the Acceptable Daily Intake (ADI) value estimated by the Joint FAO/WHO Expert Committee on Food Additives (JECFA) for benzoic acid is $0-5 \mathrm{mg} / \mathrm{kg}$ body mass [2,3]. According to the notification of the Ministry of Public Health of Thailand ((No.281) B.E.2547 (2004)), the maximum use level (ML) of benzoic acid added to food for preservative purpose is $1,000 \mathrm{mg} / \mathrm{kg}$. After oral uptake, benzoic acid is rapidly absorbed from the gastrointestinal tract and metabolized in the liver by conjugation with glycine, resulting in the formation of hippuric acid, which is rapidly excreted via urine. Nevertheless, cases of urticaria, asthma, rhinitis or anaphylactic shock have been reported following oral, dermal or inhalation exposure to benzoic acid even at low doses [4]. Due to its toxic effects, benzoic acid determination is of great importance.

Current official analytical methods regulated by Association of Official Analytical Chemists or AOAC international for benzoic acid include gas chromatography (GC) (AOAC official method 983.16) and liquid chromatography (LC) (AOAC official method 994.11). Although these official methods have advantages in terms of their high selectivity and sensitivity, they are capable of measuring benzoic acid at concentration of $\mathrm{ng} / \mathrm{mL}$ level; however, gas chromatographic official method requires expensive instruments, trimethylsilyl ester derivatization before GC analysis and 
the use of toxic organic solvents such as dichloromethane and chloroform. On the other hand, liquid-liquid extraction (LLE) and solid phase extraction (SPE) are used for sample preparations of benzoic acid prior to LC analysis [2]. Therefore, these official methods involve complicated, timeconsuming procedures, require expensive instruments and are also environment-unfriendly and harmful to the operators $[5,6]$. To overcome these problems, other analytical methods were developed.

The benzoic acid chromophore absorbs in the ultraviolet (UV) region and as a result benzoic acid can be determined directly by UV-Visible spectrophotometry which is simple and require only inexpensive instruments, such as a spectrophotometer. Codex Alimentarius Commission also recommends the use of spectrophotometric technique as the official analytical methods (ISO 5518: 2007 and ISO 6560: 1983) [7]. Nevertheless, these spectrophotometric official methods have some disadvantages since they require LLE using diethyl ether, alkaline re-extraction and purification by oxidation using acidified potassium dichromate for sample preparations of benzoic acid before determination by spectrophotometry. To overcome these sample preparation drawbacks, ultrasonic extraction can be used for this purpose. Using ultrasound, full extractions can be achieved in minutes with high extraction efficiency and reproducibility, simple and fast operation, low consumption of organic solvent, elimination of organic waste management and low consumption of fossil energy compared with the conventional extraction such as Soxhlet extraction. In addition, ultrasonic extraction is a key sample preparation step in achieving the objective of sustainable green chemistry [8]. Therefore, in this work, the sample preparation by using ultrasonic extraction was optimized for spectrophotometric benzoic acid determination in curry paste samples.

\section{Materials and Methods}

Chemicals and Reagents. All chemicals were analytical reagent grade with purity greater than 99\%. Benzoic acid (BA) was purchased from Ajax Finechem (Australia). All solvents used were purchased from the following source: ethanol was from Merck (Germany), n-propanol was from RCI Labscan (Thailand) and iso-propanol was from QRëC (New Zealand). Stock benzoic acid standard solution was prepared in n-propanol at a concentration of $10,000 \mathrm{mg} / \mathrm{L}$. A series of working benzoic acid standard solution was prepared by dilution of the stock benzoic acid standard solution with n-propanol.

Curry paste samples. Three types of curry paste; red curry paste, southern red curry paste and southern sour curry paste samples, were purchased from two shops at Subsin Market in Muang District, Songkhla, Thailand.

Sample preparation. Approximately $1 \mathrm{~g}$ of curry paste sample was accurately weighed in a $50 \mathrm{~mL}$ capped centrifuge tube. A $25 \mathrm{~mL}$-propanol was added, and then mixed vigorously for 1 min by vortex mixing. The sample was placed in a ultrasonic bath that was maintained at a frequency of $40 \mathrm{kHz}$ and $60{ }^{\circ} \mathrm{C}$ for $30 \mathrm{~min}$. The extracted sample was centrifuged for $10 \mathrm{~min}$ at $3,500 \mathrm{rpm}$. The supernatant was then transferred into a $50 \mathrm{~mL}$ volumetric flask, diluted with n-propanol up to the mark and transferred into a quartz cell for measuring an absorbance at $230 \mathrm{~nm}$ using an UV-Visible spectrophotometer.

Instrumentations. A vortex mixer (Scientific Industries, Model G-560E, USA) and a ultrasonic bath (clma, Model Transsonic Digitals T 840DH, Germany) were used for mixing and extracting during sample preparation. Spectrophotometric measurements were made on an UV-Visible spectrophotometer (Biochrome, Model Libra S50, UK).

\section{Results and Discussion}

Detection wavelength. The absorption spectra over the 190-340 nm of benzoic acid standard solution $20 \mathrm{mg} / \mathrm{L}$ prepared in three different solvents; ethanol, n-propanol and iso-propanol, are shown in Fig. 1. The maximum wavelength value of benzoic acid standard solution in all solvents was $230 \mathrm{~nm}$. Therefore, a wavelength of $230 \mathrm{~nm}$ was chosen for benzoic acid detection. 


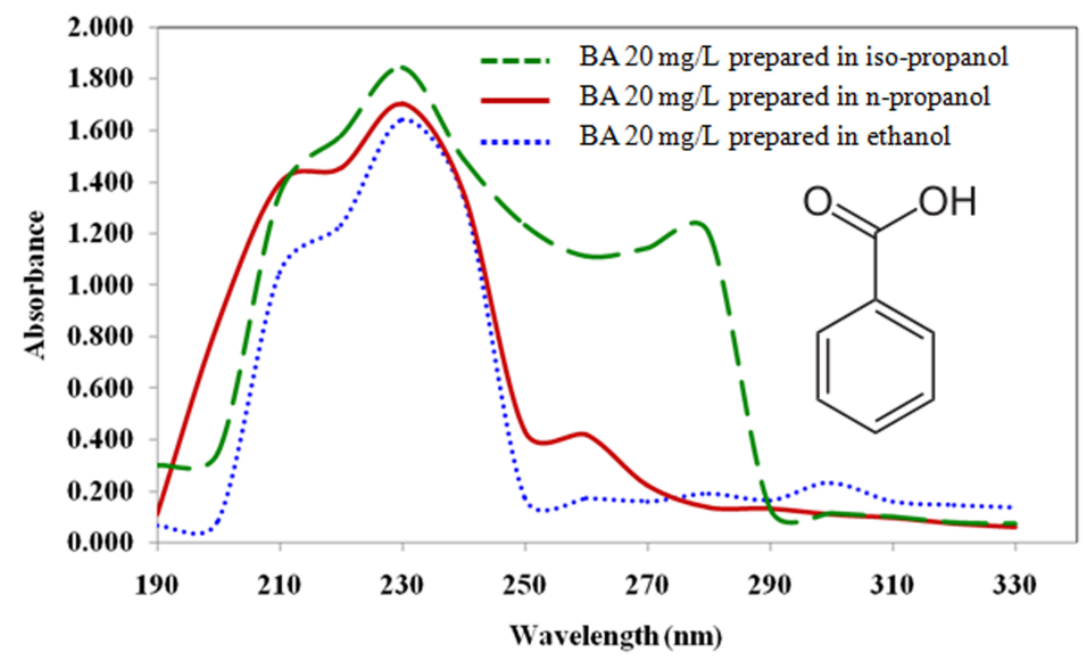

Fig. 1: Absorption spectra of benzoic acid standard solution $20 \mathrm{mg} / \mathrm{L}$ prepared in three different solvents; ethanol, n-propanol and iso-propanol

\section{Optimization of ultrasonic extraction}

Extraction solvent. Since an appropriate solvent is important for the optimization of ultrasonic extraction. Three solvents with different polarity were used for extracting benzoic acid from spiked red curry paste samples and the effect is shown in Fig. 2. According to the structure of benzoic acid consisting of a large, non-polar benzene ring attached to a small, polar carboxylic acid functional group and its physical property which is slightly soluble in water, benzoic acid is slightly polar. Therefore, solvent with similar polarity would provide good extraction efficiency. Matrix matched calibration curves were performed and prepared by plotting the absorbance versus corresponding concentration of benzoic acid in spiked red curry paste samples. On comparing the slope of matrix matched calibration curve or sensitivity of benzoic acid detection, it was found that extracting using ethanol gave lowest sensitivity (highest relative polarity of 0.654 ) and extracting using iso-propanol gave highest sensitivity (lowest relative polarity of 0.546 ). In the case of n-propanol (relative polarity of 0.617 ), it was found that there was no significant difference between extracting using n-propanol and iso-propanol compared by t-test for independent. Moreover, sensitivity obtained from extracting with n-propanol had lower standard deviation. Therefore, the most appropriate solvent for extracting benzoic acid was n-propanol.

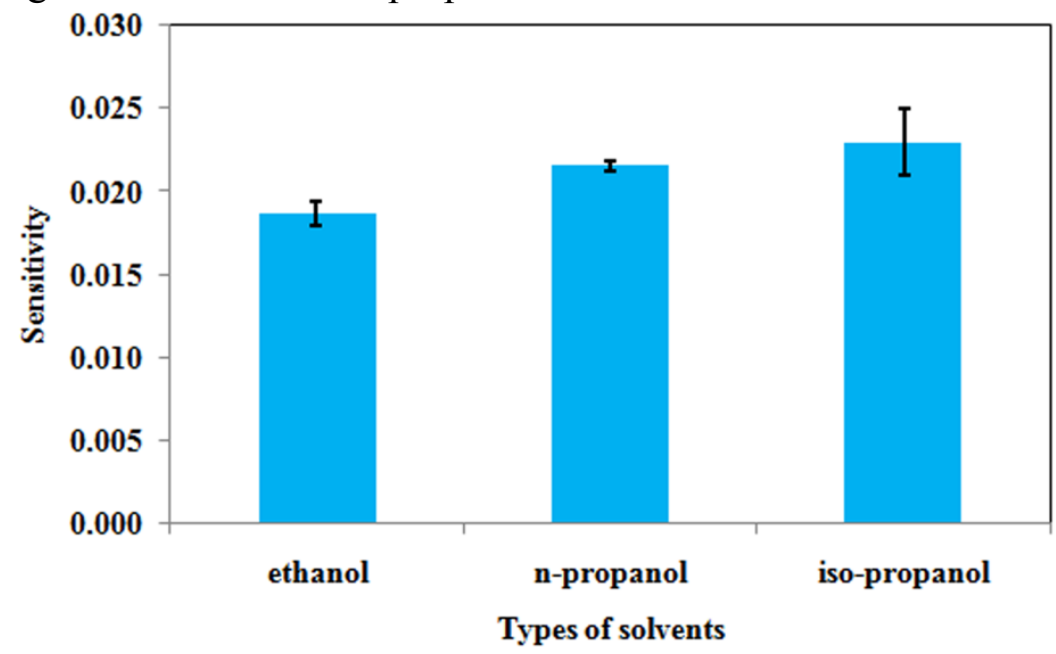

Fig. 2: Effects of extraction solvents on the sensitivity of benzoic acid detection

Extraction temperature and Extraction time. When using ultrasonic extraction, the solvent is irradiated by ultrasound, micro-bubbles form, grow, and oscillate extremely fast and eventually collapse powerfully if the acoustic pressure is high enough. These collapses, occurring near a sample, generate micro-jets and shock waves, resulting in extraction of the analyte into solvent. Extraction temperature and extraction time affect not only the extraction efficiency but also the 
composition of the extract. A higher extraction temperature means higher extraction efficiency due to the increase of the number of micro-bubbles and a larger sample-solvent contact area. However, the decrease of extraction efficiency can be occurred when the temperature is near the solvent's boiling point [8]. Similarly, increasing of extraction time improve the diffusion of interesting compound into solvent [9]. Nevertheless, long extraction time can cause degradation of the extract constituents [10]. The influences of extraction temperature and extraction time were investigated by monitoring the slope of matrix matched calibration curve prepared in spiked red curry paste samples or sensitivity of benzoic acid detection (Fig. 3). The results show the extraction efficiency increases with extraction temperature and extraction time, but at extraction temperature higher than $60{ }^{\circ} \mathrm{C}$ and extraction time higher than $30 \mathrm{~min}$, a decrease in the sensitivity of benzoic acid detection was observed. Therefore, the extraction of benzoic acid from curry paste samples can be achieved at $60{ }^{\circ} \mathrm{C}$ within $30 \mathrm{~min}$.

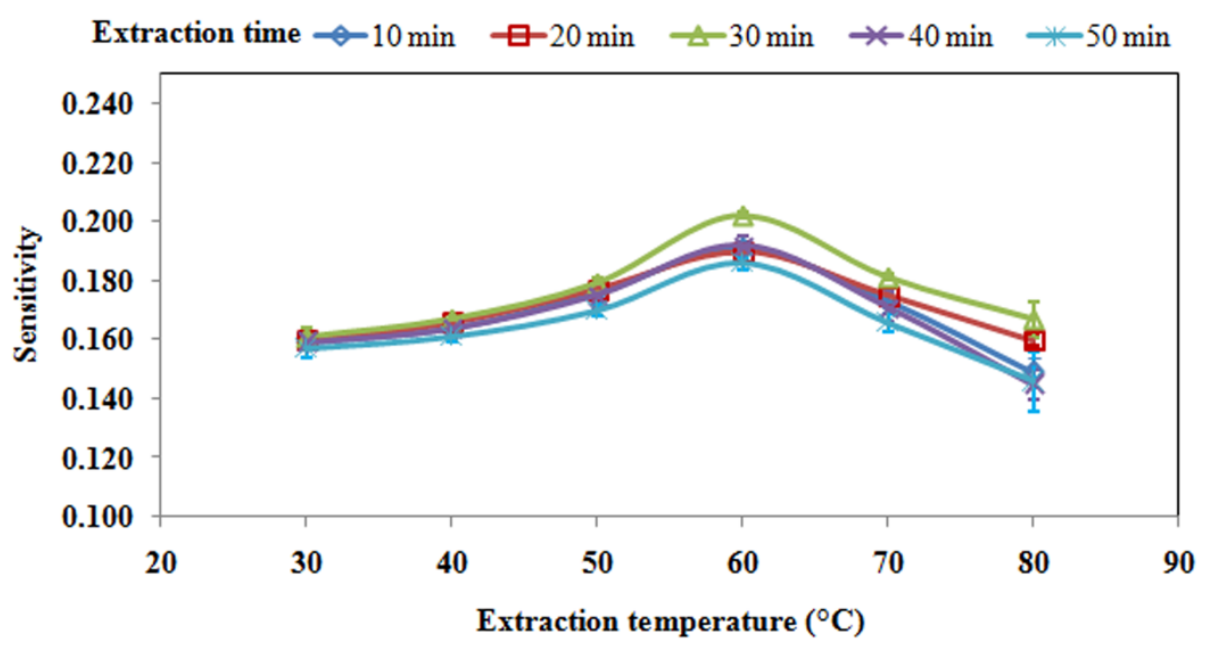

Fig. 3: Effects of extraction temperature and time on the sensitivity of benzoic acid detection

Linearity. Curry paste samples $(1 \mathrm{~g})$ were spiked with $100 \mu \mathrm{L}$ of benzoic acid standard solution from 1,000 to $20,000 \mathrm{mg} / \mathrm{mL}$ to obtain the final concentration of 100 to $2,000 \mathrm{mg} / \mathrm{kg}$ benzoic acid, they were then extracted and analyzed using an UV-Visible spectrophotometer. Matrix matched calibration curves were performed and prepared by plotting the absorbance versus corresponding concentration of benzoic acid in spiked curry paste samples. Linearity between the concentration of benzoic acid in spiked curry paste samples and the absorbance was obtained in the concentration range from 100 to $2,000 \mathrm{mg} / \mathrm{kg}$. Three types of curry paste; red curry paste, southern red curry paste and southern sour curry paste samples, were spiked, extracted and analyzed to perform matrix matched calibration curves. Fig. 4 shows the example of matrix matched calibration curve obtained from spiked red curry paste samples.

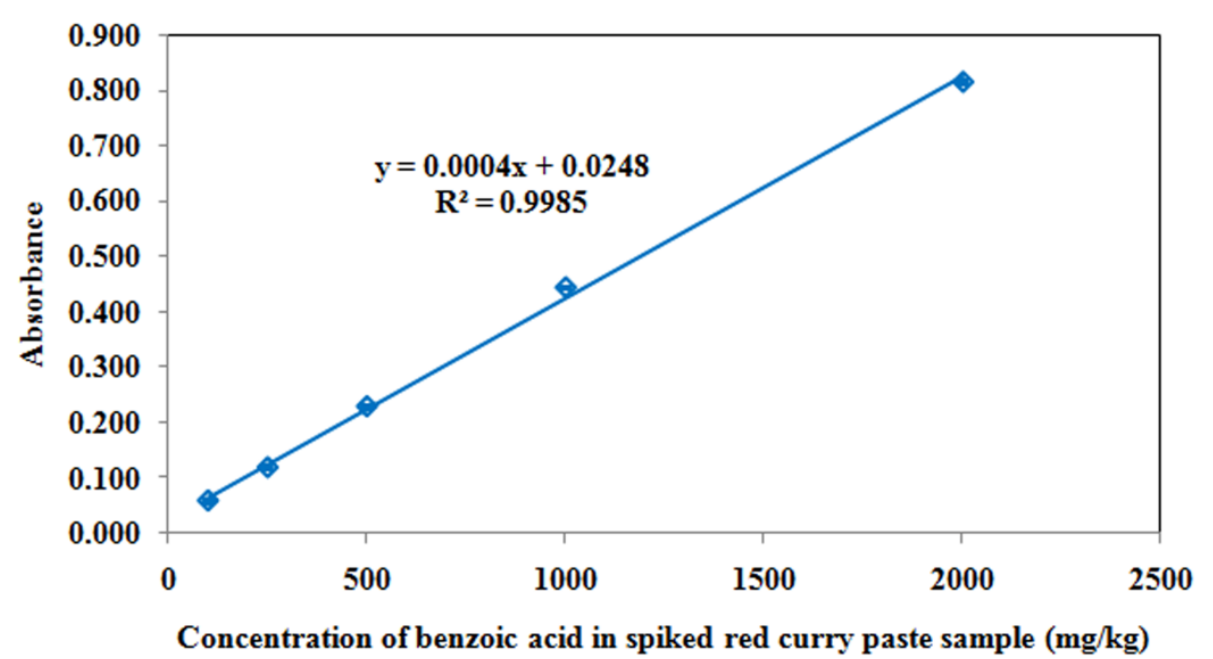

Fig. 4: The example of calibration curve obtained from spiked red curry paste samples 
Recovery and Precision. The recoveries for benzoic acid determination were also investigated. The obtained absorbance from spiked curry paste samples were used to calculate the concentration from the matrix matched calibration curve. Recovery percentage $(\% R)$ and relative standard deviation (R.S.D.) are calculated. The results of recoveries and relative standard deviation for benzoic acid determination at three different concentrations in three types of curry paste samples are shown in Table 1. Recoveries were ranged from 74.67 to $95.33 \%, 71.78$ to $97.56 \%$ and 88.00 to $106.45 \%$ with R.S.D. were 1.05 to $5.47 \%, 0.92$ to $4.27 \%$ and 0.71 to $4.22 \%$, when spiked red curry paste, southern red curry paste and southern sour curry paste samples were analyzed, respectively.

Table 1: Recoveries and relative standard deviation for benzoic acid determination at three different concentrations in three types of curry paste sample

\begin{tabular}{|c|c|c|c|c|c|}
\hline $\begin{array}{c}\text { Types of curry paste } \\
\text { sample }\end{array}$ & $\begin{array}{c}\text { Added } \\
\text { concentration } \\
{[\mathrm{mg} / \mathrm{kg}]}\end{array}$ & $\begin{array}{c}\text { Founded } \\
\text { concentration } \\
{[\mathrm{mg} / \mathrm{kg}]}\end{array}$ & $\begin{array}{c}\text { R.S.D. } \\
{[\%]}\end{array}$ & $\begin{array}{c}\text { Recovery } \\
{[\%]}\end{array}$ & $\begin{array}{c}\text { R.S.D. } \\
{[\%]}\end{array}$ \\
\hline Red curry paste sample & 375 & $325.45 \pm 15.23$ & 4.68 & $80.67 \pm 4.06$ & 5.03 \\
\hline (shop 1) & 750 & $708.95 \pm 14.30$ & 2.02 & $91.47 \pm 1.90$ & 2.08 \\
\hline$(\mathrm{n}=10)$ & 1,500 & $1,400.45 \pm 15.32$ & 1.09 & $91.83 \pm 1.02$ & 1.11 \\
\hline Red curry paste sample & 375 & $347.71 \pm 18.28$ & 5.26 & $89.19 \pm 4.88$ & 5.47 \\
\hline (shop 2) & 750 & $693.07 \pm 12.18$ & 1.76 & $90.65 \pm 1.62$ & 1.79 \\
\hline$(\mathrm{n}=10)$ & 1,500 & $1,410.15 \pm 14.87$ & 1.05 & $93.13 \pm 0.99$ & 1.06 \\
\hline Southern red curry & 375 & $296.30 \pm 10.09$ & 3.40 & $74.79 \pm 2.69$ & 3.60 \\
\hline paste sample (shop 1) & 750 & $713.75 \pm 13.71$ & 1.92 & $93.06 \pm 1.83$ & 1.97 \\
\hline$(\mathrm{n}=10)$ & 1,500 & $1,417.25 \pm 13.20$ & 0.93 & $93.43 \pm 0.88$ & 0.94 \\
\hline Southern red curry & 375 & $341.63 \pm 14.40$ & 4.22 & $89.89 \pm 3.84$ & 4.27 \\
\hline paste sample (shop 2) & 750 & $712.63 \pm 12.39$ & 1.74 & $94.41 \pm 1.65$ & 1.75 \\
\hline$(\mathrm{n}=10)$ & 1,500 & $1,445.63 \pm 13.36$ & 0.92 & $96.07 \pm 0.89$ & 0.93 \\
\hline Southern sour curry & 375 & $360.73 \pm 10.87$ & 3.01 & $92.20 \pm 2.90$ & 3.14 \\
\hline paste sample (shop 1) & 750 & $723.48 \pm 12.81$ & 1.77 & $94.47 \pm 1.71$ & 1.81 \\
\hline$(\mathrm{n}=10)$ & 1,500 & $1,411.98 \pm 10.06$ & 0.71 & $93.13 \pm 0.67$ & 0.72 \\
\hline Southern sour curry & 375 & $397.95 \pm 16.03$ & 4.03 & $101.11 \pm 4.27$ & 4.22 \\
\hline paste sample (shop 2) & 750 & $733.95 \pm 12.97$ & 1.77 & $95.36 \pm 1.73$ & 1.81 \\
\hline$(\mathrm{n}=10)$ & 1,500 & $1,422.45 \pm 13.93$ & 0.98 & $93.58 \pm 0.93$ & 0.99 \\
\hline
\end{tabular}

\section{Conclusion}

The developed ultrasonic extraction is a reliable sample preparation, which is relatively simple, fast, effective, accurate and environment-friendly. It is suited for benzoic acid determination in curry paste samples by using UV-Visible spectrophotometry.

\section{Acknowledgements}

The authors gratefully acknowledge the financial support of the Chemistry and Applied Chemistry Program, Faculty of Science and Technology, Songkhla Rajabhat University, Thailand. 


\section{References}

[1] A.M. Saeedan, S.Kh. Bamoteref, M.A. Algahri, RP-HPLC Determination of Benzoic Acid in Samples of Children Food Distributed in Aden-Yemen, Int. Res. J. Pure. App. Chem. 4(5) (2014) 507-519.

[2] R. Wood, L. Foster, A. Damant, P. Key, Analytical methods for food additives, Woodhead, Cambridte, 2004.

[3] J. Burana-osot, L. Arunsingkharat, M. Naksuk, S. Naungnamjai, T. Saetun, Validation of a HPLC Method for the Determination of Benzoic Acid and Sorbic Acid in Noodles, Chiang Mai J. Sci. 41(2) (2014) 370-382.

[4] WHO, Concise International Chemical Assessment Document; 26: Benzoic acid and sodium benzoate, World Health Organization, Geneva, 2000. Information on http://www.who.int/ipcs/ publications/cicad/cicad26_rev_1.pdf.

[5] Z.-H. Wang, J.-F.Xia, F.-Y.Zhao, Q. Han, X.-M.Guo, H. Wang, M.-Y. Ding, Determination of benzoic acid in milk by solid-phase extraction and ion chromatography with conductivity detection, Chi. Chem. Lett. 24 (2013) 243-245.

[6] X.-J. Ding, N. Xie, S. Zhao, Y.-C. Wu, J. Li, Z. Wang, Simultaneous determination of ten preservatives in ten kinds of foods by micellarelectrokinetic chromatography, Food Chem. 181 (2015) 207-214.

[7] CAC, Recommended methods of analysis and sampling (Codex STAN 234-1999), Codex Alimentarius Commission, Rome, 1999. Information on http://www.fao.org/fao-whocodexalimentarius/standards/list-standards/en/.

[8] F. Chemat, V. Tomao, M. Virot, Ultrasound-Assisted Extraction in Food Analysis, in: S. Ötleş (Eds.), Handbook of food analysis instruments, CRC, Florida, 2008, pp. 87-103.

[9] T. Prommajak, S. Surawang, N. Rattanapanone, Ultrasonic-assisted extraction of phenolic and antioxidative compounds from lizard tail (Houttuynia cordata Thunb.), Songklanakarin J. Sci. Technol. 36(1) (2014) 65-72.

[10] M.I.S. Melecchi, V.F. Péres, C. Dariva, C.A. Zini, F.C. Abad, M.M. Martinez, E.B. Caramão, Optimization of the sonication extraction method of Hibiscus tiliaceus L. flowers, Ultrason. Sonochem. 13 (2006) 242-250. 